\title{
A educação no entre lugar museu e escola: um estudo das visitas escolares ao Museu Histórico Abílio Barreto
}

\author{
Education in the in-between place of the museum and the school: \\ a study of school visits to the Abílio Barreto Historical Museum \\ La educación en el entre lugar museo y escuela: un estudio \\ de las visitas escolares al Museo Histórico Abilio Barreto
}

\begin{abstract}
SORAIA F. DUTRA*
SILVANIA S. NASCIMENTO**

RESUMO

Este artigo aborda a relação museu e escola a partir da interação desses dois espaços sociais de vivências educativas. $\mathrm{O}$ estudo compreendeu uma análise diacrônica e outra sincrônica das práticas educativas do museu na relação com a escola. Foram analisadas as práticas educativas voltadas para o público escolar desenvolvidas no Museu Histórico Abílio Barreto (MHAB). Por meio de uma pesquisa em seus registros documentais que permitiu recuperar a historicidade das praticas educativas. Uma imersão no museu no ano de 2009 permitiu acessar os modos de apropriação do museu pela escola por meio de um estudo etnográfico das ações educativas do museu e foi complementado com entrevistas semi-estruturadas. As análises apontaram a visita escolar ao museu como uma vivência de um entre lugar que institui uma prática educativa híbrida capaz de potencializar e favorecer os processos de aprendizagem da cultura. Palavras-chave: Cultura escolar. Cultura museu. Prática educativa híbrida.
\end{abstract}

\begin{abstract}
This article discusses the museum and school relationship from the interaction of these two social spaces of educational experiences. The study consisted of a diachronic and a synchronic analysis of the educational practices of the museum in relation to the school. It was analyzed the educational practices aimed at the school audience developed at the Abílio Barreto Historical Museum (Museu Histórico Abílio Barreto - MHAB), through a research in its documental records which allowed recovering the historicity of the educational practices. An immersion at the museum in the year of 2009 allowed accessing the ways the school appropriates the museum through an ethnographic study of the educational actions of the museum and it was complemented with semi-structured interviews. The analyses pointed the school visit to the museum as an experience of an in-between place that introduced a hybrid educational practice able to enhance and favour the culture learning processes.
\end{abstract}

Keywords: School culture. Museum culture. Hybrid educational practice.

\section{RESUMEN}

En este artículo se analiza la relación del museo y la escuela de la interacción de estos dos espacios sociales de experiencias educativas. El estudio consistió en un análisis diacrónico y otras prácticas educativas de los museos sincrónicos en relación a la escuela. Fueron analizados las prácticas educativas enfocadas para la escuela pública desarrollado en el Museo Histórico Abilio Barreto (MHAB). A través de una búsqueda en sus registros de documentos que permitió recuperar la historicidad de las prácticas educativas. Una inmersión en el museo en 2009 permitió a los modos de acceso de apropiación el museo por la escuela a través de un estudio etnográfico de las acciones de los museos educativos y se complementó com entrevistas semiestructuradas. Los análisis mostraron una visita escolar al museo como una experiencia de un lugar de introducir una práctica educativa híbrido capaz de mejorar y promover la cultura de los procesos de aprendizaje.

Palabras clave: La cultura escolar. Museo de la Cultura. la práctica educativa híbrido.

\footnotetext{
*Doutorado em Educação pela FAE-UFMG; EBAP - Centro Pedagógico, UFMG. E-mail: <soraiafreitasdutra@yahoo.com.br>.

**Doutora em Didática das disciplinas Paris 6; Departamento de Métodos e Técnicas de Ensino - FAE-UFMG.E-mail: <silnascimento@ufmg.br>.
} 


\section{MUSEU: UM ENTRE LUGAR}

Os museus não fazem parte da infância de milhões de brasileiros, uma vez que cerca de $79 \%$ dos municípios brasileiros não possuíam, até setembro de 2010, qualquer instituição museológica. Em 2010, o primeiro Cadastro Nacional de Museus - CNM, do IBRAM (Instituto Brasileiro de Museus) mapeou 3.025 unidades no país concentradas principalmente nas capitais litorâneas. A capital de menor taxa de concentração de museus foi Belo Horizonte (MG) com 12,9\%, seguida de Florianópolis (SC) com 14,1\% e Vitória (ES) com 16,4\%. No período do cadastramento, isso indicava que, em Minas Gerais, dos 319 museus cadastrados 41 se situavam na capital e entre os 853 municípios mineiros 149 possuíam pelo menos um museu. Nosso primeiro contato com esse categoria de equipamento cultural aconteceu tardiamente, já no período de escolarização, o que acontece com a maioria dos 80 milhões de visitantes que os museus acolheram em 2009 (BRASIL, 2011, p. 53).

O CNM aponta que do total de 1500 instituições museais que responderam ao questionário de cadastramento, $48,1 \%$ tem um setor específico para as ações educativas, e a quase totalidade deles $(96,4 \%)$ possuem atividades voltadas para o público infanto-juvenil. Dentre os museus cadastrados, $80,6 \%$ oferecem visitas guiadas para diferentes públicos "cuja modalidade mais comum é a realizada com a intermediação de monitores/guias, seguida pela visita guiada com a utilização de áudio-guia" (BRASIL, 2011, p. 122).

Denise Grinspum (2001, p. 117), em seu estudo sobre a o papel da escola na formação de públicos nos museus, analisa o universo dos pais de alunos das escolas que frequentam o Museu Lasar Segall em São Paulo. Segundo a pesquisadora, entre eles não é cultivado "o hábito de visitar museus, nem para sua satisfação pessoal, nem para o entretenimento e educação da família". Para a pesquisadora Adriana Mortara Almeida (2005, p. 25) "um dos grandes desafios dos museus é a ampliação de seus públicos, inserindo faixas de nível de renda e escolaridade que pouco saem de casa e visitam instituições culturais, mesmo as gratuitas como o MHAB".

Como profissional da educação interessada na relação entre educação e museus, vivenciamos algumas das transformações pelas quais o MHAB passou ao longo dos últimos anos: acompanhamos alunos em visitas guiadas por monitores preocupados com a transmissão de informações sobre o acervo em exposição, por meio de uma narrativa que utilizava os objetos expostos como referência na reconstituição do cenário do que seria uma moradia do século XIX; surpreendemo-nos com a ausência de visitas monitoradas no cenário da casa desmontada e, posteriormente, nos encantamos com a fluidez da brincadeira do Telefone Sem Fio e com as possibilidades didáticas da atividade denominada Roteiro de Leitura do Bonde. São evidências de um processo de transformações pelas quais passou o Museu ao longo da ultima década do século XX e primeira década do século XXI.

Mais do que a impressão de professoras visitantes, as transformações do MHAB já são conhecidas e têm notoriedade em diferentes fóruns de discussão do campo museológico com repercussão em nível local e nacional e se tornaram referência para outras instituições (AUTORA, 2012).

É, portanto, na busca da compreensão acerca dos processos educativos construídos no entre-lugar escola e museu que situamos a discussão apresentada neste artigo sobre a visita escolar ao museu.

Consideramos que o movimento de deslocamento do universo escolar para o universo museal forja um novo espaço e novo tempo de aprendizagem, e compõe uma vivência educativa situada em um entre-lugar. Essa ideia ganhou importância no contexto dos chamados Estudos Culturais, especialmente na análise de complexos processos identitários engendrados nas sociedades mestiças, do fenômeno das diásporas produzido pela nova ordem mundial ou ainda para pensar a produção literária e cultural produzida sob o signo dos deslocamentos.

A ideia de entre lugar é aqui tomada de empréstimo para pensar o processo de articulação das diferenças culturais dos museus e das escolas, que emergem no momento da visita escolar ao museu. Constitui-se em um espaço e tempo de aprendizagem híbrido, produzido na articulação de referências da cultura escolar e da cultura museal e, portanto, impregnados de diferenças culturais.

Em nosso estudo, quando focamos a visita escolar ao museu como uma vivência educativa tecida em um entre-lugar, buscamos entender como a escola imprime suas marcas sobre as ações dos museus e como o museu se distancia delas, promovendo um movimento de escolarização e paulatina desescolarização, constituindo novos objetos, estruturas e práticas educativas. Investigamos as vivências do setor educativo da instituição pública e municipal o Museu Histórico Abílio Barreto durante o ano de 2009.

\section{MUSEU E ESCOLA: UM ENTRE LUGAR DE CULTURAS}

O movimento da escola em direção aos lugares de memória (NORA, 1984) pode ser visto como um sintoma das preocupações em torno da produção das identidades por meio do estímulo à valorização e preservação da memória social e coletiva. A memória é considerada elemento fundamental da identidade, ao conferir ao 
sujeito ou grupo social um sentimento de pertencimento, continuidade, identificação e diferenciação (LE GOFF, 2003 e MENESES,1994). Podem ser também indícios da construção de novas práticas de cidadania por meio da promoção do acesso aos bens culturais e patrimoniais, associadas às preocupações específicas de professores interessados em tornar o conhecimento escolar mais significativo e prazeroso, dentre outras preocupações.

Sob a lógica do museu, por sua vez, a parceria com a escola é uma estratégia vigorosa na democratização de suas ações. O estudo de Grinspum (2001) ressalta o papel da escola como canal de aproximação de alguns grupos sociais ao museu: "as escolas acabam assumindo esse dever isoladamente, o que as tornam uma das grandes responsáveis pela relação entre alguns grupos sociais no museu" (GRINSPUM, 2001, p. 118). Nesse processo, muitas instituições museológicas mantêm em seus programas educativos ações direcionadas ao público escolar, como: cursos, estágios e oficinas aos professores, visitas monitoradas, constituição de acervos para empréstimo, conferências, entre outras ações.

Linhares (2011), no levantamento quantitativo realizado sobre as visitas escolares ao Observatório Astronômico Frei Rosário na Serra da Piedade em Minas Gerais, demonstrou que pouco mais de $2 \%$ do total de 17.902 instituições escolares públicas e privadas em atividade no estado de Minas já haviam visitado o Observatório entre os anos de 1997 a 2009. Ao analisamos a situação do MHAB no contexto das escolas municipais em Belo Horizonte, vimos um quadro bastante diferente. Um levantamento realizado pelo Setor Educativo do MHAB das escolas atendidas no período de 1998 a 2006 apontou que das 181 escolas na Rede Municipal de Ensino de Belo Horizonte em atividade, 175 delas já haviam visitado o museu em pelo menos um desses anos, o que corresponde a $94 \%$ do universo de escolas municipais.

As afinidades entre a escola e os museus não minimizam suas especificidades tanto em relação à cultura escolar quanto à cultura museal. Ao ocorrerem encontros entre essas culturas novas práticas educativas podem ser construídas. Nessa mesma direção, Marandino (2001), ao refletir sobre a relação museu e escola, pontua a necessidade de se reconhecer as especificidades de cada um desses espaços:

(...) é possível perceber que museu e escola são universos particulares, onde as relações sociais se processam de forma diferenciada, cada um com uma lógica própria. Desta forma então, é fundamental numa análise que procura estabelecer relações entre o museu e a escola, evidenciar as diferenças entre esses espaços (MARANDINO, 2001, p. 88).
Na primeira década do século XXI, escolas e museus vêm sendo marcados por transformações profundas em seus papéis e funções sociais reinventando práticas educativas e estabelecendo novas parcerias. E, como vetores de ações educativas, traçaram percursos históricos próprios, construíram linguagens específicas e propostas educativas e pedagógicas com marcas de distinção. No entanto, pesquisadores que se dedicam a reflexões sobre a educação em museu e às relações entre museu-escola apontam diferenças cruciais na forma de organização dos elementos que estruturam essas instituições: objetivos, espaços, tempos e relações pedagógicas. Nas palavras de Marandino (2001),

Museus e escolas são espaços sociais que possuem histórias, linguagens, propostas educativas e pedagógicas próprias. Socialmente são espaços que se interpenetram e se complementam mutuamente, e ambos são imprescindíveis para a formação do cidadão cientificamente alfabetizado (MARANDINO 2001, p.98).

A respeito das configurações espaciais, essas instituições guardam diferenças significativas que marcam intenções discursivas e materializam sistema de valores (ordem, disciplina e vigilância), marcos na aprendizagem sensorial e motora e toda uma semiologia com diferentes símbolos estéticos, culturais e ideológicos.

Em relação à perspectiva temporal, a estruturação de cada uma delas se dá de modo diferenciado: o tempo escolar marcado pelos relógios, horários e calendários imprime uma cultura temporal de longo prazo, seqüencial e contínua, enquanto no museu o tempo é breve e fragmentado, quase que restrito ao tempo de uma visita. Uma visita pode se constituir como única vivência singular daquele sujeito naquele de espaço cultural.

Já a dimensão pedagógica talvez seja, dentre os elementos estruturadores destas instituições, a que tenha sofrido as transformações mais significativas nas últimas décadas. No campo escolar, diferentes teorias têm orientado novas práticas pedagógicas, apontando para o estabelecimento de novas relações entre professores e alunos e entre os educadores de museu e seus públicos, relações essas pautadas nos princípios da dialogia, da interação e interatividade, elaborando novas configurações no espaço museal. Por outro lado, essas instituições compartilham o foco no papel ativo do indivíduo na construção de seu aprendizado e na concepção da aprendizagem como um processo interativo entre o sujeito e o ambiente.

Nas exposições - principais veículos de comunicação dos museus - as informações são difundidas por meio de objetos, textos, imagens, aparatos interativos, dentre outros, como meio de facilitar o diálogo com o público. 
A escola, por sua vez, tem sido cada vez mais aberta às inovações tecnológicas e ao uso de múltiplos mediadores no processo de ensino-aprendizagem, embora haja uma centralidade na comunicação escrita.

Faz-se necessário, portanto, um olhar mais atento para esse novo contexto discursivo dos museus, a fim de compreender melhor o lugar da oralidade e da escrita nos espaços museais, aspectos considerados centrais na cultura escolarizada e que foram, por muito tempo, referendadas pelos museus. As formas como os museus veiculam suas informações (o discurso museal), por meio da mediação de instrumentos e sujeitos envolvidos nas interações, podem informar aspectos daquilo que se constituiu o que se denomina cultura museal.

Ao analisarmos as ações educativas, tanto as do museu voltadas para escola quanto aquelas da escola em relação ao museu, como práticas culturais colocamos em circulação um conjunto de reflexões que não se acham circunscritas a um único campo de produção acadêmica. Procedemos uma análise documental das ações educativas do Museu Histórico Abílio Barreto tomando como marco a sua revitalização em 1993. Realizamos uma pesquisa etnográfica para o acompanhamento de um ano das ações cotidianas do Setor Educativo, acrescidas de entrevistas com professores, a fim de conhecer os objetivos que impulsionaram a visita ao Museu. E buscamos uma triangulação entre os diferentes contextos de produção dessas fontes.

\section{UM ESTUDO DAS VISITAS ESCOLARES DO MHAB}

Entender a visita escolar ao museu como uma vivência educativa híbrida, tecida no entre lugar museu e escola, significou a necessidade de levantamento de informações nos dois contextos educativos.

No âmbito do museu, interessava-nos conhecer a historicidade da ação educacional a fim de compreender o significado atribuído à educação. Para isso procedemos a uma investigação documental que nos permitiu traçar o percurso da sua trajetória histórica que levou à consolidação do seu Programa de Educação Patrimonial. Ainda no âmbito museu, visando conhecer o contexto extra-verbal desse programa, empreendemos uma pesquisa etnográfica que permitiu a observação cotidiana da prática educativa do museu durante a visita escolar.

No âmbito da escola, para conhecer o significado atribuído pelos professores à visita e os modos de apropriação do MHAB realizamos entrevistas demandando aos professores as motivações para a realização da visita, o processo de preparação prévia e os desdobramentos no retorno à escola.
Considerando a natureza do estudo, valorizamos a interpretação e a compreensão de significados, ao invés dos experimentalismos que perseguem leis e regularidades. Em maior ou em menor grau, nos apropriamos de técnicas e procedimentos da Teoria Fundamentada (STRAUSS e CORBIN, 2008, p. 22-23) por conter princípios que se aproximam da natureza do problema a ser investigado:

a) a necessidade de sair a campo para descobrir o que estava realmente acontecendo;

b) a relevância da teoria, baseada em dados, para o desenvolvimento de uma disciplina e como base para a ação social;

c) a complexidade e a variabilidade dos fenômenos e das ações humanas;

d) a crença de que as pessoas são atores que assumem um papel ativo para responder a situações problemáticas;

e) a percepção de que as pessoas agem com base em significados;

f) a compreensão de que o significado é definido e redefinido através da interação;

g) a sensibilidade para a natureza evolutiva e reveladora dos fatos (processo);

h) a consciência da inter-relação entre condição (estrutura), ação (processo) e consequências.

No processo de tratamento das informações procuramos, em um primeiro momento, realizar uma descrição capaz de conferir inteligibilidade aos dados, seguido de um ordenamento conceitual e, finalmente, procurou-se tecer algumas reflexões teóricas acerca dos problemas levantados.

A escolha pela etnografia possibilitou a imersão no campo e permitiu traçar um mapa daquilo que "contava" como ação educativa para o Museu na relação com o público escolar. Imergir nos museus para entender os significados gestados no 'contexto museal' pressupôs a adoção de uma perspectiva de análise pautada na descrição dos fenômenos a partir de uma visão interior de uma vivência cultural, na direção do que se denomina perspectiva êmica, ou seja, "aquela que se ocupa de descrever uma cultura vista de dentro, contemplada naquilo que é relevante para os membros do grupo" (GREEN et alli, 2005, p.79). Assim, entender "o que acontece no museu" é tentar interpretar os significados construídos pelos sujeitos envolvidos em diferentes práticas e vivências museais, sem, contudo, deixar de ocupar a posição de observadora externa (ética). Nossa compreensão de que a visão externa aguça a compreensão interna se apoia na afirmativa de Sahlins (2006, p. 12-13): "precisamos de uma outra cultura, para conhecer outra cultura". Nessa medida, o estranhamento é um procedimento metodológico (GOMES, 2009) essencial para se acessar o ponto de vista do outro. Realizar um 
duplo movimento capaz de transformar o exótico em familiar e o familiar em exótico.

A adoção da etnografia como lógica investigativa e da observação etnográfica como recurso metodológico permitiu a descrição densa, da cultura institucional do museu, em uma aproximação com os sujeitos dessa instituição. A expressão, descrição densa, utilizada por Geertz (1986) emprestada de Gilbert Ryle, descreve fenômenos culturais buscando ultrapassar a superfície, e visa perceber os significados das ações dos sujeitos no contexto em que foram gestados. Ao observarmos as suas práticas aproximamos de suas representações e formas de apropriações e significação do museu.

A aplicação de diferentes procedimentos metodológicos criou a necessidade de uma triangulação dos dados oriundos das diferentes situações de produção. Para melhor compreensão dos procedimentos utilizados em cada uma das etapas da pesquisa apresentamos uma descrição dos mesmos no Quadro 1, abaixo.

A descrição densa de todo conteúdo documental e registros de campo, associado a uma interpretação indiciária (GINSBURG, 1989), nos permitiu encontrar pistas, traços e marcas daquilo que passou a ser reconhecido como ação educativa destinada ao público escolar, gestada no contexto museal e nos modos de apropriação dos museus feitos pelos professores.

$\mathrm{O}$ acesso às informações acerca das apropriações que os professores efetuaram do museu, seus objetivos, possibilidades e limites, foram complementadas com a realização de entrevistas semi-estruturadas realizadas com os 13 professores e 2 técnicos educacionais que acompanharam alunos de escolas públicas do ensino fundamental e médio ao museu.

\section{Resultados e discussão}

Fundado em 1943 para abrigar a memória da cidade de Belo Horizonte, o Museu recebeu inicialmente a denominação de Museu Histórico de Belo Horizonte, sendo posteriormente rebatizado de Museu Histórico Abílio Barreto no ano de 1967, em homenagem ao seu fundador. Ao completar 50 anos em 1993, o museu empreendeu um processo de revitalização orientado por uma nova abordagem museológica, apoiado em três eixos basilares: preservação/investigação/comunicação, que pretendeu transformá-lo num "centro irradiador de cultura, dedicado à memória e à história de Belo Horizonte", nas palavras de Isabela Guerra (2006, p.104).

O Projeto de Revitalização do MHAB encontrou eco tanto nos processos de revitalização de outras instituições brasileiras, orientadas, sobretudo, pelos princípios da 'nova museologia', quanto na renovação no campo do conhecimento histórico. Ele se desenrolou em um cenário de mudanças políticas e culturais delineadas na cidade de Belo Horizonte a partir de1992 com a eleição de um prefeito cujo projeto se alinhava aos interesses das camadas populares e se abria a um diálogo mais estreito com diferentes setores da sociedade.(AUTORA, 2012).

Muitos museus, não de forma linear, tão pouco generalizada, vivenciaram renovações e redefinições do seu papel social, implementando mudanças estruturais na sua concepção, promovendo alterações nas suas funções científico-documentais, educacionais e culturais no anseio de compatibilizar suas atividades com as novas demandas sociais. Assim, de templos privilegiando a contemplação e sacralização de uma memória oficial, os museus foram desafiados a se posicionarem como instituições culturais

Quadro 1. Mapa dos dados

\begin{tabular}{|l|l|l|l|}
\hline \multicolumn{1}{|c|}{ Etapas da Pesquisa } & \multicolumn{1}{|c|}{ Local } & \multicolumn{1}{c|}{ Volume dos Dados } & \multicolumn{1}{c|}{ Descrição } \\
\hline Pesquisa documental & $\begin{array}{l}\text { Arquivos do Setor Educativo e } \\
\text { Arquivo Administrativo do MHAB }\end{array}$ & Aproximadamente 34 documentos & Fonte Primária \\
\hline $\begin{array}{l}\text { Etnografia / Notas } \\
\text { de campo }\end{array}$ & $\begin{array}{l}\text { Museu Histórico Abílio Barreto } \\
\text { (Espaços administrativos, Sala } \\
\text { multiuso e Espaços expositivos) }\end{array}$ & 144 folhas (148×210 mm espiraladas) & $\begin{array}{l}\text { Observação: } \\
\text { Visitas escolares; } \\
\text { Reuniões do Grupo de Estudos } \\
\text { Reuniões administrativas } \\
\text { Aspectos do funcionamento } \\
\text { cotidiano do museu }\end{array}$ \\
\hline Entrevistas & $\begin{array}{l}\text { Locais previamente definidos pelos } \\
\text { professores (biblioteca, sala de } \\
\text { aula; sala da coordenação, sala dos } \\
\text { professores) }\end{array}$ & $\begin{array}{l}\text { Entrevistados: 15 } \\
\text { No horas: aproximadamente 6h26min }\end{array}$ & $\begin{array}{l}\text { Dados pessoais (nome sexo) } \\
\text { e profissionais do professor } \\
\text { (atuação e formação). } \\
\text { Constou de um roteiro } \\
\text { organizado em 6 temas com } \\
\text { questões derivadas de cada tema. }\end{array}$ \\
\hline $\begin{array}{l}\text { Filmagens } \\
\text { (Documentação } \\
\text { complementar) }\end{array}$ & $\begin{array}{l}\text { Espaços expositivos do Museu } \\
\text { Histórico Abílio Barreto }\end{array}$ & $\begin{array}{l}\text { Foram filmadas 07 visitas } \\
\text { escolares, sendo 4 escolas } \\
\text { municipais, 1 estadual e } \\
\text { 2 particulares }\end{array}$ \\
\hline
\end{tabular}

Fonte: AUTORA, 2012, p. 82. 
participativas e atuantes na sociedade. Para Silvania Nascimento (2010):

as mutações ocorridas na museologia do século XX, de forma simplificada, refletem a modernização dos espaços culturais cuja complementaridade entre coleção e arquitetura envolve o projeto de museu e o que chamei de dessacralização de espaço museológico representada pela criação dos chamados museus de sociedade que incorporaram, já, uma visão ampliada do conceito de museu (NASCIMENTO, 2010, p. 251).

No ambiente dos museus, vários autores (NASCIMENTO e VENTURA, 2001; COLINVAUX, 2005; MARANDINO, 2008, ALMEIDA, 2006) apontam a preocupação crescente com a construção de novas formas de interação entre o visitante e o objeto em exposição que extrapole a mera dimensão contemplativa e se transformem em vivências dialogadas com o visitante que já não se limita a um receptor passivo, mas um 'compositor', capaz de 'integrar em suas lembranças e esquecimentos a vivência sensível de interpretação do objeto museal" (NASCIMENTO, 2005, p. 225).

$\mathrm{O}$ aumento no atendimento ao público escolar superior a $100 \%$ e a ampliação do atendimento às escolas públicas, no período de 1992 a 1996, atestam o vigor dessa reorientação das ações do Museu. A Gráfico 1 permite uma melhor visualização dessa alteração ao longo do período que se estendeu de 1988 a 1996.

Gráfico 1. Comparativo de Atendimento das diferentes Redes de Ensino no MHAB - 1988 a 1996

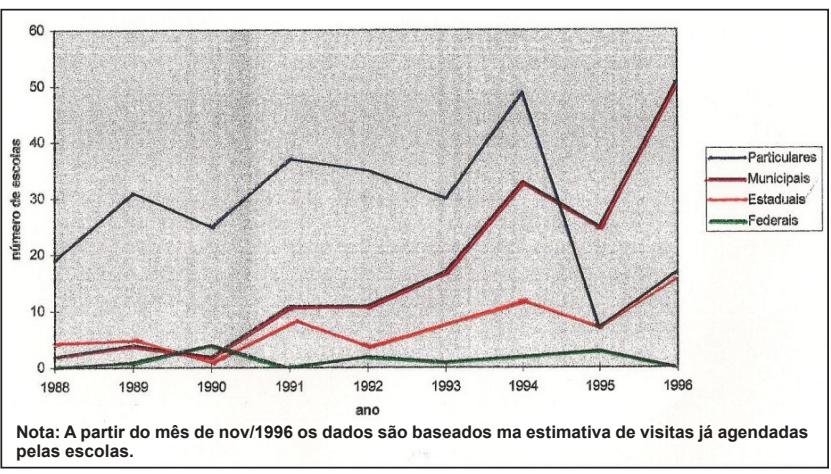

Fonte: MHAB: Gráficos. Arquivo do Setor Educativo.

Até a adoção de um amplo Programa de Educação Patrimonial, evidenciou-se uma trajetória de redefinições e escolhas pautadas em uma nova política museológica, assentada nos seguintes pilares:

a) ruptura com a concepção celebrativa do passado, com a memória oficial e com a visão de tempo unidirecional. Em favor de um projeto de História fundamentado em novos problemas e dilemas da vida urbana em suas múltiplas dimensões e pluralidade de memórias e marcado pela multiplicidade de tempos históricos;

b) compromisso com a democratização e preocupação com as múltiplas dimensões da vida social urbana;

c) clareza da vocação do museu histórico, comprometido com o desenvolvimento de uma consciência crítica sobre a cidade;

d) ampliação do universo de ação do Museu, para além dos seus espaços formais (ações extramuros);

e) desenvolvimento de um Programa de Educação Patrimonial, que tomasse o patrimônio cultural da cidade como centro das suas atividades educativas;

f) dinamização da mediação centrada nos objetos da cultura material, como fontes para produção do conhecimento histórico e desenvolvimento de uma consciência patrimonial.

Todos esses fatores contribuíram para a consolidação de um programa educativo voltado para o desenvolvimento da consciência crítica sobre a cidade. A partir da redefinição da sua identidade institucional e da clareza da sua vocação como equipamento cultural responsável pelo ordenamento da memória da cidade o Museu se confirmou como importante referência na produção, reflexão e difusão da história de Belo Horizonte, consolidando o seu Programa de Educação Patrimonial e a escola municipal se constituiu em sua principal interlocutora.

Os ruídos anunciam a chegada dos visitantes e, ao romper o silêncio do museu, inicia-se uma vivência tecida no encontro de dois universos distintos. A cultura escolar se entrecruza com a cultura museal no espaço da exposição e se multiplicam em diferentes vivências individuais em contato com os objetos ali expostos. Essa é a mais importante marca que temos gravada em nosso caderno de campo.

As visitas escolares aos espaços não formais de educação e cultura assumem, no dia-a-dia da escola, várias definições que ora a aproximam de uma atividade de lazer, ora de estudo, embora essas designações não sejam excludentes. Segundo Linhares (2011), os termos atribuídos a essa vivência: excursões, passeios, turismo pedagógico, saída de campo, trabalho de campo, viagem, viagem de campo, viagem técnicas, variam com a finalidade e os significados que os sujeitos the atribuem. Linhares (2011) ao se deparar com a ausência de uma definição para o termo 'visitas escolares', desenvolveu a seguinte acepção:

um recurso didático utilizado pelos professores para organizar uma atividade curricular intencionalmente planejada, servindo para desenvolver e complementar conteúdos curriculares, mediantes saídas direcionadas para ambientes externos ao espaço físico da escola ou sala de aula. São, portanto, atividades educativas de cunho pedagógico e não necessariamente contidas no plano de curso (LINHARES, 2011, p. 149). 
Em nosso estudo, consideramos que as visitas podem ser capazes de mobilizar potencialidades diversas e permitir agregar sentidos múltiplos ao ato de aprender. $\mathrm{O}$ deslocamento espacial da escola para o museu favorece outros deslocamentos de diferentes naturezas: curricular, estético, pedagógico, hierárquico, cognitivo, dentre outros.

Durante nossas observações das visitas ao MHAB, anotamos no caderno de campo traços de interações entre os professores, mediadores dos museus, alunos e outros visitantes ao longo de um ano de observação de campo (Fev/2009 a Fev/2010). Reconstruímos essas notas na forma de 21 fragmentos narrativos que apresentam os atores e suas ações, diferentes usos do museu pelo público escolar, cenários diversos que expressa a complexidade envolvida na relação entre museu e escola. Longe de cobrir o leque de possibilidades de interações entre nesse espaço, a análise das situações nos possibilitou uma visão global do cenário dinâmico do museu povoado por seus visitantes escolares. Limitamos neste artigo o destaque para 3 fragmentos de situações pedagógicas ali constituídas a título de exemplo da investigação. A situação 1 remete diretamente ao ensino da História, apontando a apropriação do museu como fonte para o conhecimento histórico e para a compreensão do fazer do historiador remetendo ao currículo escolar de História.

\section{Situação 1}

- A professora trabalha com seus alunos a compreensão acerca do fazer do historiador e faz a visita ao museu tomando-o como lugar de memória e, portanto, fonte de saber histórico.

(Visita Escolar, Escola Municipal Ensino Fundamental em 17/02/2009)

$\mathrm{Na}$ situação 3 o Museu aparece como um espaço que possibilita o conhecimento sobre a cidade, capaz de qualificar o processo de ensino-aprendizagem. $\mathrm{O}$ estreito vínculo com o currículo escolar aparece não diretamente relacionado ao conteúdo histórico, mas à temática da cidade estudada por meio de um projeto multidisciplinar. Assim, o museu extrapola seu campo de ação para além das fronteiras da história e se coloca como uma referência para se pensar a cidade.

\section{Situação 3}

- A professora desenvolve um projeto pedagógico sobre a cidade de Belo Horizonte - Projeto BH Sustentável - que envolve diferentes campos do conhecimento. A visita ao museu faz parte do processo de levantamento de elementos e informações que serão tratados e aprofundados em sala de aula.

(Visita Escolar: Escola Estadual Ensino Médio em 05/03/09)
A situação 5 explicita uma relação direta como o conteúdo histórico estudado em sala de aula. E nesse caso, o museu é visto como fonte de informações sobre o passado da cidade, sugerido uma compreensão do museu como depositário do "antigo" a ser visto. Assim, a ideia de que o museu guarda o passado como ele ocorreu parece nortear a ação do(a) professor(a). Por outro lado, a significação do Museu como guardião de uma memória que não já pode ser acessada exclusivamente pelos mecanismos que a escola dispõe, fica também evidente. Nessa medida, o museu soma-se à escola no processo do trato com a memória e com a História.

\section{Situação 5}

- A professora está estudando a História do município de Belo Horizonte e organizou a visita ao museu com o objetivo de conhecer informações sobre a "parte antiga da cidade".

(Visita Escolar: Escola Municipal Ensino Fundamental em 19/03/09)

A partir dos fragmentos sintetizamos que nem sempre a visita ao museu histórico da cidade guarda uma relação direta com o conteúdo do campo disciplinar da História, como poderíamos inicialmente supor. Os interesses dos professores se apresentam articulados ao projeto pedagógico em diferentes campos disciplinares, contemplam os interesses de projetos coletivos de ensino envolvendo temas sobre a cidade. Podem também fazer parte de uma política da escola de acesso aos bens culturais, como uma ação que visa à educação para o patrimônio.

Conhecer os objetos; observá-los; ter contato com eles e tomá-los como fontes/documentos no estudo da História, foram aspectos que impulsionaram professores na realização da visita. A preocupação com a preservação dos objetos da cultura material e a possibilidade desses objetos contribuírem para os processos de identificação e construção de identidade, embora de modo incidental, figuraram entre os interesses dos professores. A visualização dos objetos aparece como elemento importante para o professor, seja pela sua mera capacidade ilustrativa seja pela dimensão educativa contida no ato de ver.

Outro objetivo que mobilizou a visita ao museu estava ligado ao conceito de Cultura (24 incidências), como mostra a Figura 1. A possibilidade de vivência cultural ou lugar que 'guarda' a cultura, destaca-se entre os objetivos declarados pelos professores para justificar a visita durante as entrevistas. A existência de uma cultura objetivada no acervo e nos bens culturais guardados pelo museu parece também orientar a busca do professor pela instituição. 


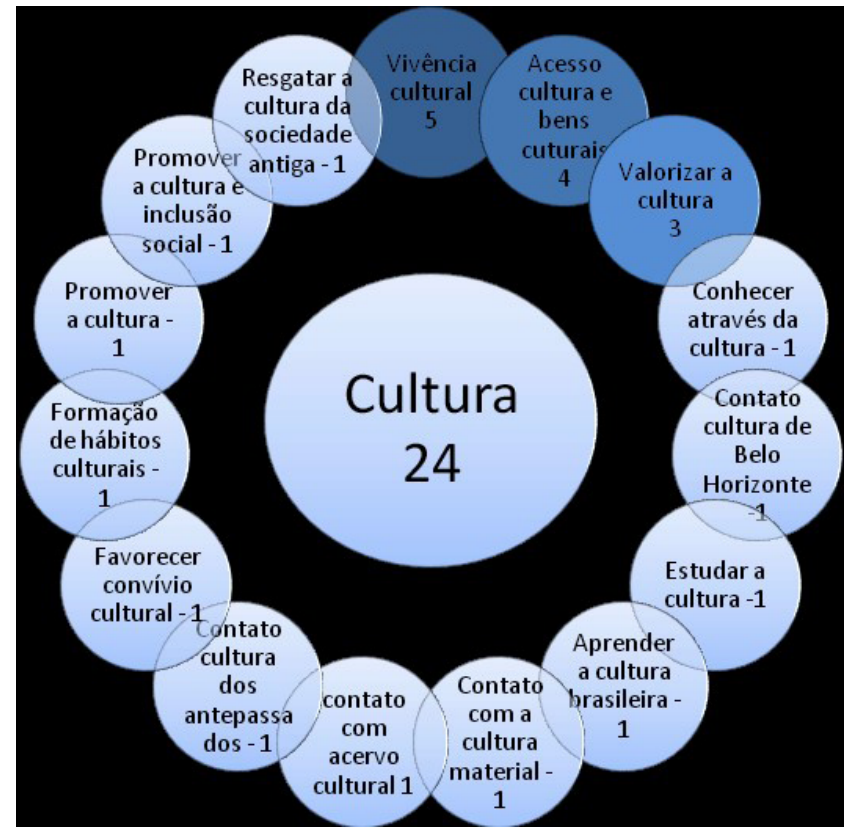

Fonte: AUTORA, 2012, p. 226.

Figura 1. Atributos à palavra cultura retirados dos 31 fragmentos narrativos.

A ideia de que essa cultura precisa ser conhecida, estudada, aprendida, apropriada, contatada, acessada, resgatada e valorizada, mobiliza a preocupação pedagógica do professor e o faz promover a vivência cultural no museu. A ideia de que o contato com a cultura promove conhecimento aparece também associada a esse objetivo.

Do vasto material de entrevista, destacamos neste artigo apenas alguns excertos nos quais os professores enfatizam a importância da formação de um hábito cultural de visita aos museus. No excerto 1, Lúcia justifica a visita ao museu como uma iniciativa pouco presente no contexto familiar de seus alunos. A escola foi, então, apontada como mediadora nesta formação cultural:

\section{EXCERTO 1}

Lúcia: - o pessoal gosta de parque, gosta de clube, gosta de tudo, mas museu é uma coisa que se a escola não levou; a família não é muito engajada, não é ligada na educação, a memória, a cultura do Brasil como um todo. a família não leva, então eles não tem acesso. então eu acho que a única forma de acesso que eles tem é através da escola. então a escola aqui, sempre a gente procura, além da gente integrar com os conteúdos que a gente está trabalhando, olhar, levar pra esse lado também do incentivo dos alunos conhecerem um museu. a importância dele pra história, pra memória, né?

Pes:- hunrum.

Lúcia: - então nesse sentido também que a gente tentou dar enfoque. (AUTORA, 2012, p. 254)
O valor dos objetos como testemunhos da História foi também considerado um aspecto relevante pela professora Larissa para avaliar a escolha pela visita ao Museu no excerto 2:

\section{EXCERTO 2 \\ Larissa: - (...) achei interessante a visita. agora uma coisa interessante na visita ao museu é o aluno, ele ver o objeto. \\ Pes:- hunrum. \\ Larissa: - porque geralmente quando a gente estuda em sala de aula, eles vêem imagens. lá não, eles vivenciaram um espaço antigo, uma estrutura antiga. eles puderam colocar as mãos, puderam ver os objetos, porque as vezes a gente conta, fala, vê nos livros, mas é uma coisa muito distante do aluno. se a gente tem condições de levar o aluno nestes espaços é como se eles vivenciassem né? \\ Pes: - hunrum. \\ Larissa: - aquilo tem mais significado para eles, tem mais sentido pra eles. (AUTORA, 2012, p. 255)}

Embora não seja nosso objetivo enveredar pelas discussões do campo da formação e dos saberes docentes, o que os dados levantados apontam é, de um lado, o caráter lacunar dessa formação no que se refere aos temas ligados à educação em museus, à relação museu e escola e área afins e, do outro, a constituição por parte dos professores de um repertório de saberes a partir dessa prática educativa.

As análises das entrevistas permitiram destacar que as vivências de formação continuada nessa área foram incidentais. A visita aos museus mediada pela escola ou fora dela e a frequência ao curso oferecido pelo museu (decrescente nos últimos anos) constituíram-se um espaços de formação muitas vezes declarado. Talvez esse cenário ajude a entender, em parte, a postura pouco propositiva do professor na cena e a demanda desses pela presença do mediador no contexto da visita.

\section{ENTRE O VISÍVEL E O SENSÍVEL}

Compreender o museu como ambiente de aprendizagem sensível, significa estar aberto à fruição estética. Para Meneses (2003), "os sentidos são pontes que permitem ao sujeito comunicar-se com o universo". Para esse autor, museu não é o lugar da palavra escrita, ela já tem seus suportes, mas o lugar da transformação da percepção e os educadores precisam explorar o que define a personalidade do museu.

A visita ao museu pela escola pode ser compreendida como uma vivência que institui uma prática educativa híbrida. Ao aproximar elementos dos dois contextos educativos - museus e escolas - ela encerra as potencialidades que cada um deles. $\mathrm{O}$ conjunto de análise 
desenvolvido no percurso dessa investigação permitiu destacar vários entre lugares no hibridismo que constitui a visita das escolas aos museus.

$\mathrm{O}$ MHAB foi percebido pelos professores como um lugar que encerra múltiplas possibilidades educativas: preserva, acolhe, produz conhecimento histórico, oportuniza o acesso aos conhecimentos sobre a cidade, possibilita romper com a rotina da escola, permite ver objetos, facilita a aproximação com aspectos da memória coletiva das pessoas que viveram e vivem em Belo Horizonte, possibilita o lazer e promove conscientização. Enfim, para os professores a visita é, acima de tudo, uma promessa de expansão das possibilidades educativas e de aprendizagens.

A visita escolar ao museu é gestada no contexto das práticas escolares, movido por um desejo dos professores pelo conhecimento da instituição, mas ocorre no contexto das práticas educativas museais. Logo em sua preparação, a visita se posiciona fortemente em um entre lugar, de expectativa e desejo. Nesse aparente paradoxo é que reside toda a riqueza dessa vivência em mobilizar formas de aprendizagem da cultura.

A importância que o MHAB atribui ao desenvolvimento do conhecimento sobre a cidade a partir do seu acervo estabelece uma convergência entre ele e as escolas. Para os professores, a vivência da visita ao MHAB se constitui em outra forma de aprender sobre a cidade e sua história, e reúne possibilidades de aprendizado que extrapolam aquelas do universo escolar. Embora vistos principalmente como fontes para a construção do conhecimento, a dimensão estética dos objetos, também é ressaltada como aspecto importante nos processos de aprendizagem.

Talvez a vivência no museu venha nos convidar a reconsiderar o valor da visita escolar, não numa perspectiva que negue o valor da abstração reflexiva, mas como um processo que permite construir novos significados mediados pela vivência sensível do espaço e tempo museal. A visita cria possibilidades de deslocamentos capazes de subverter a rotina da escola e suas estruturas rígidas. Ela permite uma brecha na forma dominante da estruturação do conhecimento escolar e dos sistemas formais de educação.

$\mathrm{Na}$ vivência da visita é possível ter contato com uma forma de aprender que dispensa o registro e os instrumentos de aferição do conhecimento aprendido, suscitando outra relação com o saber, alicerçada no prazer pelo conhecimento e, nessa medida, mais distanciada da forma dominante na escola, sobretudo em tempos de uma educação por competências.

Os imperativos do sistema educativo que avaliam e classificam podem ser suavizados pela oportunidade de aprender pelo prazer e pela sensibilidade no museu. Essa pequena subversão não significa ruptura e abandono da lógica escolar, até pela preponderância na condução do processo educativo na sociedade expressas no tempo de duração; permanência; continuidade; respaldo; legitimidade; dentre outros, em contraposição ao tempo breve e fugaz da visita.

Nos espaços do museu, ao invés das carteiras e mesas da sala de aula, apresenta-se o cenário da exposição. Para ser vista, apreciada, contemplada, admirada são convocados os múltiplos sentidos do visitante. A "exploração" dos objetos em exposição convida à movimentação mais livre dos visitantes; instiga a estabelecer uma relação corporal com objeto a ser conhecido.

O museu é também um espaço da ordem, da disciplina e da vigilância, e nessa medida, é um espaço que regula o comportamento do sujeito. A movimentação mais 'livre' no espaço do museu é, contudo, limitada pelas suas regras de funcionamento, que são imperativos da forma museal.

Se as especificidades da aprendizagem no ambiente do museu não forem conhecidas pelo professor, a insegurança do entre lugar pode ser um limitador no processo de trocas de vivências. Assim, conhecer as especificidades educativas do museu torna-se fundamental para que a visita possa agregar aos visitantes conhecimentos, habilidades, vivências sensoriais e atitudes. Ao mesmo tempo o museu precisa tornar a sua forma conhecida, projetando-a para fora dos muros, no cruzamento com a escola; compreendê-la melhor, entender seus objetivos, seu currículo abrindo possibilidades de outras pontes.

As diferentes formas de apropriação do MHAB pelos professores evidenciaram uma realidade multifacetada que não se enquadra em visões estereotipadas e homogeneizadoras. A despeito dos inúmeros obstáculos que permeiam o cotidiano escolar, das incertezas das condições de trabalho e dos desafios da condição docente, os professores foram capazes de reinventar práticas e se lançar na aventura de novas possibilidades educativas.

Esperamos que os dados levantados e as nossas análises possam trazer subsídios para os estudos na área da educação em museus e, mais especificamente na relação museu e escola.

\section{REFERÊNCIAS}

ALMEIDA, Adriana M. Análise das Pesquisas realizadas pelo Instituto de Pesquisa Doxa, 2005. In: MHAB - Relatório Téenico Final do Projeto "Pesquisa de Público para Avaliações das Exposições e dos projetos de Educação Patrimonial do Museu Histórico Abílio Barreto. Belo Horizonte, outubro de 2005. Manuscrito (31fl).

ALMEIDA, Adriana M. Avaliação de Ações Educativas em Museus. In: $1 \underline{0}$ Encontro das Ações Educativas em Museus da cidade de São Paulo. São Paulo: 2006. Disponível em:<http:// vs40.pytown.com:8080/portal/.event pres/encontros/dim-educ/ doc/mesa2/a-mortara-apres/> Acesso em: 15/03/2008. 
BRASIL. Ministério da Cultura. Museus em Números. Vol. 1. IBRAM. MINC. Disponível em: <http://www.museus.gov.br/ wp-content/uploads/2011/11/museus_em_numeros_volume 1 . pdf $>$. Acessado em: 07 jun. 2015.

CHAGAS, Mario. Educação, museu e patrimônio: tensão, devoração e adjetivação. In: Revista eletrônica IPHANEducação Patrimonial, n. 3, jan./fev. de 2006.

COLINVAUX, Dominique. Museus de ciências e psicologia: interatividade, experimentação e contexto. In: Revista História, Ciências Saúde, Manguinhos (Rio de Janeiro: Casa de Oswaldo Cruz/Fiocruz), v. 12, p. 79-91 2005. Disponível em: <http://www.scielo.br/scielo.php?script=sci arttext\&pid $=\mathrm{S} 0104-9702005000400005 \&$ lng $=$ pt\&nrm $=$ isso $>$. Acesso em: $18 / 03 / 2007$.

DO NASCIMENTO, Silvania S. O desafio de construção de uma nova pratica educativa para os museus. In:VIDAL, Diana G.; FIGUEIREDO, Betânia G. Museus: dos gabinetes de curiosidade à museologia moderna. Belo Horizonte, MG: Argvmentvm; Brasília, DF: CNPq, 2005

NASCIMENTO, Silvania S. As Luzes d(n)o Vale: expressividades de memórias e identidades em movimento. Belo Horizonte: UFMG/PROEX, 2010.

DUTRA, Soraia F. A educação na fronteira entre museus e escolas: um estudo sobre as visitas escolares ao Museu Histórico Abílio Barreto. Tese (Doutorado em Educação) - Universidade Federal de Minas Gerais, Belo Horizonte, 2012.

GOMES, Ana Maria R. Explorando a cultura, entre o estranhamento e a escolarização. In: YASBEK, Dalva C.; ROCHA, Marlos B. M. (Orgs). Cultura e História da Educação: intelectuais, legislação, cultura escolar e imprensa. Juiz de Fora: Editora UFJF, 2009.

GREEN, J. L., DIXON, C. N.; ZAHARLICK, A. A etnografia como uma lógica de investigação. In: Educação em Revista, Belo Horizonte, n. 42, dez. 2005.

GRINSPUM, Denise. Educação para o Patrimônio: conceitos, métodos e reflexões para formulação de política. In: Simpósio Internacional Museu e Educação - conceitos e métodos. São Paulo, MAE-USP-MAM, 2001.

GRUNBERG, Evelina. Educação Patrimonial: utilização dos bens culturais como recursos educacionais. Cadernos do CEOM, Unoesc-Chapecó, ano 14, n. 12, jun. 2000.
GUERRA, Isabela T. Onde mora minha História? In: Anais do Seminário de Ações Educativas - Cultura e Educação: parceria que faz história. Belo Horizonte: Mazza Edições; Instituto Cultural Flávio Gutierrez/MAO, 2007.

LE GOFF, Jacques. Documento/Monumento. In: História e Memória. Campinas, SP: Editora Unicamp, 2003.

LINHARES, Fernando Roberto da Costa. Os Objetivos das visitas escolares a um observatório astronômico na visão dos professores. Dissertação (Mestrado em Educação) - Faculdade de Educação, Universidade Federal de Minas Gerais, 2011.

MARANDINO, Martha. Educação em museus: a mediação em foco. São Paulo: Geenf/FEUSP, 2008.

MARANDINO, Martha. Interfaces na relação museu-escola. In: Cad. Cat. Ens. Fís., v. 18, n. 1, p. 85-100, abr. 2001. Disponível em: $<$ http://www.geenf.fe.usp.br/conteudo/arquivo/ Interfaces_na_relacao_museu_escola.PDF $>$. Acesso em: 15 abr. 2007.

MENESES, Ulpiano B. O museu de cidade e a consciência da cidade. In: SANTOS, Afonso (Org.). Museu Histórico Nacional. Rio de Janeiro, 2003.

MENESES, Ulpiano T. B. Do teatro da memória ao laboratório da História. In: Anais do Museu Paulista, São Paulo, 1994. Vol. 2.

NASCIMENTO, Silvania S DO e VENTURA, Paulo Cezar S. Mutações na construção dos Museus de Ciências. In: Revista Pro-Posições, Faculdade de Educação - Unicamp, Campinas, v. 12, n. 1 (34), 2001.

NORA, Pierre. Les lieux des mémoires. Paris: Gallimard, 1984.

SHALINS, Marshal. O pessimismo sentimental e a vivência etnográfica: por que a cultura não é um objeto em vias de extinção. Rio de Janeiro: Mana, 1997. Vol. 3 (parte I): p. 41-73; (parte II): p. 103-150.

SAHLINS, Marshal. História e cultura. Apologias a Tucídides. Rio de Janeiro: Jorge Zahar, 2006.

STRAUSS, Anselm L.; CORBIN, Juliet. Pesquisa Qualitativa: Técnicas e Procedimentos para o Desenvolvimento. Porto Alegre: Artes Médicas, 2008.

Submetido em 07/06/2015

Aprovado em 08/06/2016 